\title{
Cousin marriage and congenital anomalies in a multiethnic birth cohort
}

\author{
S Raeburn \\ Emeritus Professor of Clinical Genetics, University of Nottingham, UK \\ TITLE Risk factors for congenital anomaly in a multiethnic birth cohort: an \\ analysis of the Born in Bradford study.
}

AUTHORS Sheridan E, Wright J, Small $\mathrm{N}$ et al.

JOURNAL Lancet 2013. http://dx.doi.org/I0.1016/S0 I40-6736(13)6 I I32-0

DECLARATION OF INTERESTS Professor Raeburn is the Editor of the JRCPE.
Correspondence to S Raeburn,
Publications Office, RCPE
9 Queen Street
Edinburgh EH2 IJQ, UK

tel. +44 (0) I3I 2473652

e-mail

Sandy.Raeburn@nottingham.ac.uk

\section{SUMMARY}

Congenital abnormalities (CAs) cause stillbirths, infant deaths and many later life disabilities. Infant mortality rates from different communities reflect levels of such birth defects and are often used to compare populations and determine key risk factors. Understanding causation and the high risk groups is clearly worthwhile, with a view to future prevention. Sheridan and his multidisciplinary team present results from a birth cohort collected from 2007 to 2011 in which data from II,396 mothers, participating in the Born in Bradford study, were linked with details of 386 congenital anomalies identified (and validated) in the same period.

This meant that putative risk factors for congenital anomaly could be compared with minimal bias and that confounding variables could be analysed separately. For example, earlier studies, associating higher rates of birth defect with frequent cousin marriages in British Pakistani families, were difficult to interpret since the methodologies did not take account of levels of social deprivation in different groups. This study gets that right. The core finding is confirmation that consanguineous marriage is a major risk factor for CAs, even after adjustment for deprivation. Specifically, increasing deprivation alone was not associated with higher congenital anomaly rates; nor was obesity and other nutritional disorders. Non-consanguineous couples (of all ethnic groups) had a CA rate of $2.5 \%$ compared with a rate of $6.5 \%$ for first cousins, giving a multivariate risk ratio of 2.19 (confidence interval 1.67-2.85). However, in all ethnic groups studied, maternal education level (diploma level or above) was correlated with lower CA rates.

\section{OPINION}

Early investigations of the risks of consanguineous marriage were often tainted by uncritical condemnations of the practice. Communities that encouraged cousin marriage were often blamed as irresponsible, even though there were few evidence-based assessments of the risk. Nevertheless, worldwide, cousin marriage is currently chosen by more than I billion couples.' In a commentary published with Sheridan's paper, ${ }^{2}$ Alan Bittles indicates defects of earlier studies, including bias in design, especially relating to ascertainment as well as excessively small sample sizes. ${ }^{3}$ Bittles also points out the lack of information about marriages within 'birarderis' (relatives via the male lineage but not related as full cousins) in British Pakistani communities. Endogamy (marriage between individuals from the same founding tribe) can also increase the likelihood of autosomal recessive disorders occurring in the offspring because such partners may both carry the same recessive mutations due to identity by descent.

One of the aspects not tackled by this study is an analysis of the proportion of couples whose increased risk might have been anticipated by assessing a carefully prepared family history of CAs in family members. ${ }^{4}$ Counselling these couples prospectively about their higher risks might have enabled them to consider more options. Was the lower CA rate in those of all ethnic groups who had achieved higher educational levels due to their recognition of a greater risk?

Accurate information, as in this excellent readable paper, supports informed choices; it is much better than raw, ill-informed prejudice of the recent past. Decisions about consanguinity can now be informed by data clarifying the degree of risk relative to non-consanguineous marriages alongside studies that explore the context of cousin marriages and indicate possible options to reduce risks ${ }^{1-4}$ and point towards other causes of CAs. ${ }^{5}$

\section{REFERENCES}

I Bittles AH. Consanguinity in context. Cambridge: Cambridge University Press; 2012. http://dx.doi.org/I0.1017/CBO978II39015844

2 Bittles $\mathrm{AH}$. Consanguineous marriages and congenital anomalies. Lancet 20I3; pii.

3 Bundey S, Alam H. A five-year prospective study of the health of children in different ethnic groups, with particular reference to the effect of inbreeding. Eur J Hum Genet 1993; 1:206-19.

4 Qureshi N, Guilbert P, Raeburn JA. Consanguinity and genetic morbidity in a British primary care setting: a pilot study with trained link workers. Ann Hum Biol 2003; 30:140-7. http://dx.doi. org/I0.1080/030I44602I000033427

5 Szpiech ZA, Xu J,Pemberton TJ et al. Long runs of homozygosity are enriched for deleterious variation. Am J Hum Genet 2013; 93:90-102. http://dx.doi.org//0.1016/j.ajhg.2013.05.003 